American Journal of Pharmaceutical Education 2018; 82 (10) Article 6460.

\title{
RESEARCH
}

\section{Implementation and Assessment of a Novel APPE Intersession Course to Assess Near-Terminal Student Competence}

\author{
Allison B. Blackmer, PharmD, ${ }^{\mathrm{a}}$ Megan Thompson, PharmD, ${ }^{\mathrm{a}}$ Jason M. Brunner, PhD, ${ }^{\mathrm{a}}$ \\ Toral Patel, PharmD, ${ }^{a}$ Joseph J. Saseen, PharmD ${ }^{\mathrm{a}, \mathrm{b}}$ \\ ${ }^{a}$ University of Colorado Skaggs School of Pharmacy and Pharmaceutical Sciences, Anschutz Medical Campus, Aurora, \\ Colorado \\ ${ }^{\mathrm{b}}$ University of Colorado School of Medicine, Anschutz Medical Campus, Aurora, Colorado \\ Submitted April 12, 2017; accepted July 3, 2017; published December 2018.
}

Objective. To provide a novel culminating experience that assesses student competence and achievement of five curricular outcomes during the P4 year.

Methods. This two-week Intersession course provided faculty assessment of student competence after completing five of seven Advanced Pharmacy Practice Experiences (APPEs). Students completed written pre-work assignments generated from real-world experiences from APPEs. Faculty assessed and provided feedback to improve students' competency on curricular outcomes related to four course components: clinical case, drug information, clinical pearl and reflection. After incorporating faculty feedback, students verbally presented to faculty and peers for additional assessment during the in-class portion of the course.

Results. There were 149 students who completed the course in 2016; 145 (97\%) demonstrated achievement of ability-based outcomes. Using the Kirkpatrick's Evaluation Model, level 1 data (reaction) indicated $93 \%$ of students and $100 \%$ of faculty believed the course was valuable. Level 2 data (learning) revealed that $80 \%$ of students and $85 \%$ of faculty agreed/strongly agreed learning occurred. Level 3 data (behavior) demonstrated increased student performance on assessments between pre-work and in-class components. Preliminary level 4 data (results) indicated this course complemented learning from previous courses and met the intended purpose.

Conclusion: This novel Intersession course provided structured faculty assessment of student competence during the final experiential year and successfully provided a near-final evaluation of student competence of core curricular ability-based outcomes.

Keywords: intersession course, experiential, education, pharmacy curricular assessment, curriculum

\section{INTRODUCTION}

Intersession courses have been included in various health professions curricula. ${ }^{1,2}$ Success has been achieved when these types of courses use clinical experiences to motivate learning. Intersession courses are conducted over a short period of time that occurs between semesters or defined learning experiences. Intersession courses are typically accelerated where students complete defined types of academic work, and when scheduled near the end of a health professions training program, have the potential to target advanced clinical skills that require

Corresponding Author: Joseph J. Saseen, Skaggs School of Pharmacy and Pharmaceutical Sciences, University of Colorado Anschutz Medical Campus (C238), 12850

E. Montview Blvd., Aurora, CO 80045. Tel: 303-724-2656.

E-mail: joseph.saseen@ucdenver.edu integration of multiple concepts and elements of a curricular program.

The University of Colorado Skaggs School of Pharmacy and Pharmaceutical Sciences (SSPPS) implemented a revised, renewed curriculum for the class of 2016. This renewed curriculum incorporates novel concepts and new courses, including a required Intersession (two credit hours) course during the experiential year. The Intersession course is designed to be a culminating course where faculty assess student competency. The concepts of this course are consistent with the curricular priorities of the Doctor of Pharmacy (PharmD) programs that are outlined in the 2013 Center for the Advancement of Pharmacy Education (CAPE) Educational Outcomes. ${ }^{3}$ From a strategic pedagogical perspective, it allows assurance of appropriate student achievement of key curricular abilitybased outcomes (ABOs) at a near-terminal time in the 


\section{American Journal of Pharmaceutical Education 2018; 82 (10) Article 6460.}

PharmD program. Importantly, remediation with reassessment for students failing to meet expectations is included. For the class of 2016, the Intersession course was strategically scheduled during the first two weeks of January, after completion of five of the required seven Advanced Pharmacy Practice Experiences (APPEs). Students complete seven APPEs: hospital practice $(n=2)$, community practice $(n=1)$, ambulatory care $(n=1)$, medication therapy management $(n=1)$, electives $(n=2)$. The rationale for the timing of this course is to assess and verify achievement of several SSPPS PharmD curricular $\mathrm{ABOs}$ prior to graduation and to allow for improvement of identified deficiencies during the final two APPEs and reassessed by faculty at the completion of the APPE year.

The overall intent of the Intersession course is to assess achievement of key ABOs during the experiential year, but it also has several additional purposes. This is the final experience where students bring experiences gained during APPEs back into the classroom, where systematic peer and faculty mentorship, and feedback based on assessment occurs. The Intersession course assignments represent work completed during APPEs. In some cases, the work is expanded upon to meet individual assignment criteria (eg, to meet specifications of assignment templates). However, the content comes from the students' real-world experiences in experiential settings. The Intersession course followed four guiding principles: to further instill professionalism through collegial interactions with peers and faculty; to re-engage students on campus for professional activities; to cultivate the spirit of community; and to provide additional valuable and rewarding learning experiences. This course requires students to share the extent of learning that occurs during the $\mathrm{P} 4$ year in the many diverse practice settings, and further augments preceptors' assessment of students. Furthermore, the Intersession course facilitates a global assessment of all students at a focused individual level, and provides assessment data on the effectiveness of the revised $\mathrm{P} 1-\mathrm{P} 3$ curriculum. The purpose of this manuscript is to describe this innovative Intersession course at the University of Colorado, including the course design and a comprehensive assessment strategy used to evaluate initial successes. This study was granted exempt status by the Colorado Multiple Institutional Review Board.

\section{METHODS}

The SSPPS Intersession course is designed to be a near-terminal assessment of student achievement of five of the University of Colorado's curricular ABOs (Table 1). To demonstrate achievement/competence, students must achieve a $\geq 72.5 \%$ in the course. There were 149 P4 students who completed this course in 2016. The five ABOs are included as core components and are assessed during required APPEs. However, because of variability among APPE rotations, it is difficult to ensure that all five competencies are being assessed consistently. As such, the Intersession course is a way to provide a consistent assessment of student competency related to these specific ABOs for individual student development and for overall curricular assessment.

Student achievement of these ABOs is assessed using four graded course components: Clinical Pharmacy Case Conference (CPCC), Drug Information (DI) Activity, Clinical Pearl In-Service, and Professional Reflection (Table 1). The overall course grade is a composite score comprised of each course component as follows: Clinical Case Conference (50\%), DI Activity (20\%), Clinical Pearl In-Service (20\%), and Professional Reflection $(10 \%)$. The first three components include pre-work and in-class assignments, whereas the Professional Reflection

Table 1. Course Ability-Based Outcomes and the Assessed Course Component

\begin{tabular}{lc}
\hline Ability-Based Outcome [theme] & Course Component(s) \\
\hline Conduct a patient-centered assessment [assessment] & Clinical Pharmacy Case Conference \\
Design, implement, evaluate and adjust a patient-centered pharmacy care plan [plan] & Clinical Pharmacy Case Conference \\
Retrieve, evaluate, and use professional and lay information in a critical and scientific & Clinical Pharmacy Case Conference \\
manner that enhances the practice of pharmacy [evidence-based medicine] & Drug Information \\
& Clinical Pearl \\
Exhibit the highest standards of professional and ethical behavior in pharmacy practice & Clinical Pharmacy Case Conference \\
[professionalism] & Drug Information \\
& Clinical Pearl \\
Communicate effectively using multiple strategies to improve health outcomes & Reflection \\
[communication] & Clinical Pharmacy Case Conference \\
& Drug Information \\
\end{tabular}




\section{American Journal of Pharmaceutical Education 2018; 82 (10) Article 6460.}

is an in-class activity only. Students spend approximately 40 hours on pre-work assignments and approximately 20 hours on in-class activities. For those assignments with pre-work, extensive feedback is provided to improve subsequent in-class activities. Individual faculty devoted approximately 10-20 hours to complete student assessment rubrics. Value Added Sessions are included as an ungraded component in this course.

\section{Clinical Pharmacy Case Conference}

The Clinical Pharmacy Case Conference (CPCC) is the culminating experience within the curriculum for students to demonstrate proficiency and competence in assessing and presenting a patient case. Students share experiences by presenting a complex patient case from an APPE to peers and faculty. This assignment consists of one pre-work assignment and three in-class components. Students identify a patient case from one of the first five APPEs that requires critical thinking, problem-solving, and decision-making skills. The patient must have at least three medium or high priority problems that require pharmacotherapy intervention or are related to drug therapy. At least one problem must meet one of the following criteria: is less common but familiar to the audience or a well-known problem that presents in a challenging way. Students collect all necessary clinical information during the APPE rotation in which the patient was encountered. Students complete a CPCC pre-work assignment and electronically submit it though an online learning management system. This submission includes a systematic assessment of the three problems, and a thorough, yet succinct, evidence-based, patient-specific recommendation for each problem. A core team of full-time faculty, who teach in the Pharmacotherapy courses, grade the prework case submissions using a detailed and standardized rubric that provides assessment with in-depth feedback in the form of extensive written comments and a score. Feedback is an essential component of the CPCC. Each student's case submission is used for the in-class portions of the CPCC, which includes three successive and progressive case rounds. The progressive case round format was employed to provide students the opportunity to observe and learn from peers and faculty.

During Round 1, each student individually presents their pre-work case in groups of 6 to 8 students using the initial case submission as a handout and following a standard patient presentation format. Although the written pre-work handout may not be modified, students are expected to update the verbal presentation of the case based on the feedback provided by faculty who graded the pre-work submission. Presentations are a maximum of 10 minutes, followed by one reflective and one content-based question. A multi-tiered assessment of each student is conducted, which includes faculty and peer assessment. Each student's Round 1 presentation, pre-work scoring, faculty scoring of the verbal presentation and peer ranking are used to determine the top 2 students from each Round 1 group.

During Round 2, students are reorganized into small groups of 3-4 students that includes one of the top students from Round 1 (called the case originator). Students work collaboratively within groups to create and then deliver an expanded, formal presentation (using slides) of the case originator's case that also includes additional content in the format of an evidence-based discussion of therapeutic options for the three patient problems. The case is modified based on feedback provided during Round 1 and input from all group members. Round 2 presentations are presented to four other similar groups and are 25- minute presentations followed by up to 10 minutes of therapeutic-based questions by faculty and peers. Faculty and peer student groups conduct assessments, and results of these assessments are tallied to identify the top group from each of the five Round 2 sessions.

In Round 3, the top 5 groups provide the same presentation from Round 2, with modification based on the Round 2 feedback. These presentations occur in a 600-seat auditorium; all students attend the Round 3 presentations. All SSPPS faculty, P1s, P2s, and P3s, and IPPE/APPE preceptors are invited to attend these recorded presentations. From these top five presentations, a core group of faculty identify the top case. Additionally, the case originator for the top group is acknowledged with an award at graduation.

\section{Drug Information Activity}

The Drug Information (DI) activity is a concluding evidence-based medicine experience for students to demonstrate proficiency and competence. This component includes two pre-work and one in-class assignment. The first pre-work assignment requires students to submit two DI questions from the first four APPEs stated in the form of an open ended, concise and specific question. Eligible questions require utilization of primary literature and must have been asked during the first four APPEs. Course directors review and select one of the questions for the student to submit a complete answer for the second pre-work assignment. Students have one month to complete the second pre-work assignment. The second prework assignment requires a comprehensive review of the literature and answer to the DI question, using a standardized template that requires a final evidence-based summary and clinical recommendation. Faculty grade this assignment and provide feedback aimed at improving student knowledge and performance. 


\section{American Journal of Pharmaceutical Education 2018; 82 (10) Article 6460.}

The in-class portion of the DI activity more closely simulates a real-world situation. Students have 4 hours to answer an assigned DI question, using the same format as the second pre-work assignment. Although in clinical practice many DI questions are answered in less than 4 hours, the course directors determined that 4 hours would mimic real-world scenarios while allowing students enough time to complete all portions of the written assignment. Simultaneous release of the assigned DI questions via email occurs the morning of the in-class activity. Each student is assigned a question that was completed as pre-work by a peer. Students have full access to all University of Colorado Health Sciences Library online resources. At the end of the 4-hour timeframe, students are grouped (8-10 students per group) according to the clinical topic area from pre-work assignments (eg, pediatrics, oncology, ambulatory care, general medicine) for verbal presentations of the answer to the assigned DI question. Students have 6 minutes to present the completed assigned DI question to the group. Then, the student who originally answered the DI question and the student who just presented engage in a brief 2-minute dialogue to discuss findings, noting similarities and differences, and evaluating why answers may have been similar or dissimilar. Upon completion, both students answer questions from a faculty member and peer students.

\section{Clinical Pearl In-Service}

The Clinical Pearl In-Service is a final experience for students to demonstrate proficiency and competence in presenting concise clinical and practical information. This component includes one pre-work and one in-class assignment. As the pre-work assignment, students submit a Clinical Pearl topic and one multiple-choice question related to the topic for approval. This Clinical Pearl topic must meet at least one of the following criteria: a medication approved for use within the past two years, a medication the student first saw used during APPEs, a medication used for an uncommon/off-label indication, or a medication used with an unusual dose/interval, route of administration, or dosage form. The multiple-choice question is edited by the course director and included in the quiz at the end of all presentations. This provides assessment of effectiveness of the presentation (self-assessment) as well as assessment of knowledge gained from those attending the presentation.

The in-class component requires students to create a 1-page double-sided handout on the approved Clinical Pearl topic and to deliver a 5-minute presentation to a group of peers and faculty. Handouts and presentations must be appropriately referenced and include the title/topic, background information, clinical evidence regarding the topic, and recommendations. Students had autonomy to determine the best way to present the Clinical Pearl presentation in terms of format. However, formal presentation slides were not allowed. Groups include 30-32 students, arranged such that no repeating topics are included within one group. After each presentation, the student fields questions from faculty and peers. At the end of half of the presentations, students complete a 10-question quiz using edited versions of the multiple-choice questions submitted during pre-work assignments. This cycle is repeated for the other half of the students.

\section{Professional Reflection}

Each student reflects on an experience over the past four years in the form of a written reflection assignment. Students are randomly assigned to write a reflective and narrative letter to an incoming P1, P2, P3 or P4 student audience. Each student is required to reflect on educational experiences and provide advice on what incoming students should expect in the upcoming academic year.

\section{Value Added Sessions}

Value added sessions are designed to instill a sense of lifelong learning by mimicking a professional conference. Several educational sessions and workshops are offered. Value Added Sessions are optional components that are not graded. Categories for Value Added Sessions are professional development, therapeutic knowledge, and board preparation. The structure of the Value Added Sessions is similar to a professional meeting where students have the choice to attend one of several concurrently running sessions. Faculty and staff at the school volunteered for and presented the Value Added Sessions.

\section{RESULTS}

Before reporting our results, we will first describe the necessary assessments made. The Kirkpatrick's FourLevel Training Evaluation Model was used to assess the outcomes of this course. ${ }^{4,5}$ This method included levels of analysis: Level 1 (Reaction; what are the students' and faculty's reactions to the program?), Level 2 (Learning; do students demonstrate learning of knowledge, skills and attitudes of the specified course learning outcomes?), Level 3 (Behavior; do students demonstrate application of learning?), and Level 4 (Results; what is the effect of the program on the institution?). This method provided varied and well-rounded perspectives on the course.

Descriptive statistics including frequency of responses, item mean and standard deviation were used to describe survey data. Surveys used a 5-point Likert scale: $4=$ strongly agree, $3=$ agree, $2=$ disagree, $1=$ strongly disagree, $0=$ unable to comment (faculty surveys only). For 


\section{American Journal of Pharmaceutical Education 2018; 82 (10) Article 6460.}

analysis of data, zeroes were treated as missing data and were not included in the analysis. Independent samples t-test for equality of means was used for unpaired comparisons and paired samples t-test was used for comparisons of paired data. Data were also explained using 95\% confidence intervals. Student and faculty survey data were analyzed using a 2-tailed Spearman Correlation with a significance level set at .01 . Comparisons between faculty and student survey responses were conducted using Mann Whitney U test. A significance level was set at .05 for all statistical analyses. All data were analyzed using IBM SPSS Statistics 23 (Armonk, NY).

\section{Level 1 Data: Reaction}

For the Level 1 analysis, all students and faculty members involved in the course completed a survey that evaluated their reactions (perceptions) of the course. At the end of the survey, they were also asked to provide open-ended, anecdotal comments regarding the aspects of the course that they found to be most successful and those that could be improved.

Overall, 140 of 149 students (94\%) and 25 of 30 faculty $(83 \%)$ responded to the survey. The course was well liked and successful, with $93 \%$ and $100 \%$ of students and faculty, respectively, agreeing or strongly agreeing with the statement (Table 2). When comparing faculty responses to student responses, faculty responses were slightly more favorable for the statement: "This course re-engaged the students with their classmate and provided valuable and rewarding experiences" $(p=.03)$. Students were receptive to Value Added Sessions and found them relevant to individual development as evidenced by a high attendance, with an average of 41 students attending each session (range 12 to 71 ).

Open-ended, anecdotal feedback provided by students and faculty was favorable. The themes that emerged from students responses were: enjoyed the format, specifically the opportunity to present and learn from peers $(\mathrm{N}=35)$; enjoyed challenging assignments that simulated clinical practice, especially DI $(\mathrm{N}=9)$; $\mathrm{CPCC}$ was valuable $(\mathrm{N}=11)$ but did not care for the competitive nature $(\mathrm{N}=38)$; appreciated the lifelong learning aspect of the Clinical Pearl component $(\mathrm{N}=32)$; enjoyed the Value Added Sessions $(\mathrm{N}=41)$; and many wanted more $(\mathrm{N}=27)$.

Faculty open-ended, anecdotal feedback indicated that the course enhanced verbal and written communication, re-engaged students with each other and the school, fostered professionalism, and encouraged lifelong learning. Several faculty commented on the usefulness of the extensive faculty feedback to students and highlighted the positive impact this had on student growth and development. The faculty identified a few areas that needed improvement, specifically the need to gain efficiencies in the time/effort required for pre-work grading and in-class presentations, grade variability between faculty graders and the necessity to create more uniformity, and the need for additional practice with DI-related activities earlier in the curriculum.

\section{Level 2 Data: Learning}

Student learning was assessed using performance data and a post-course survey for Level 2 analysis. Based on grading for the course components, students achieved a high-level of performance for each individual assignment: CPCC, mean 86.7\% (SD 8.2); DI, mean 87.6\% (SD 9.8); Clinical Pearl, mean 92.1\% (SD 7.2); and Reflection, mean $88.7 \%$ (SD 11.8). The mean final course grade was $89 \%$ (SD 6.8).

Student survey questions were created to map to $\mathrm{ABOs}$ that were assessed in this Intersession course (Table 3$)$. Student $(n=140)$ and faculty $(n=25)$ responses to

Table 2. Level 1 Data: Survey of Student and Faculty Perception

\begin{tabular}{|c|c|c|c|c|c|c|}
\hline & \multicolumn{5}{|c|}{ N (\%) } \\
\hline & & $\begin{array}{l}\text { Unable to } \\
\text { Comment* }\end{array}$ & $\begin{array}{l}\text { Strongly } \\
\text { Disagree }\end{array}$ & Disagree & Agree & $\begin{array}{c}\text { Strongly } \\
\text { Agree }\end{array}$ \\
\hline \multirow[t]{2}{*}{$\begin{array}{l}\text { Student Response } \\
\quad(\mathrm{N}=140)\end{array}$} & $\begin{array}{l}\text { This course re-engaged me with my classmates } \\
\text { and provided valuable and rewarding } \\
\text { experiences }\end{array}$ & $\mathrm{N} / \mathrm{A}$ & $0(0.0)$ & $10(7.1)$ & $91(65.0)$ & 39 (27.9) \\
\hline & $\begin{array}{l}\text { The Value Added Sessions were useful and } \\
\text { relevant }\end{array}$ & N/A & $0(0.0)$ & $2(1.4)$ & $87(62.1)$ & $51(36.4)$ \\
\hline \multirow[t]{2}{*}{$\begin{array}{l}\text { Faculty Response } \\
\qquad(\mathrm{N}=25)\end{array}$} & $\begin{array}{l}\text { This course re-engaged the students with their } \\
\text { classmates and provided valuable and } \\
\text { rewarding experiences }\end{array}$ & 2 & $0(0.0)$ & $0(0.0)$ & $12(52.2)$ & $11(47.8)$ \\
\hline & $\begin{array}{l}\text { The Value Added Sessions were useful and } \\
\text { relevant }\end{array}$ & 11 & $0(0.0)$ & $0(0.0)$ & $6(42.9)$ & $8(57.1)$ \\
\hline
\end{tabular}




\section{American Journal of Pharmaceutical Education 2018; 82 (10) Article 6460.}

Table 3. Survey Question Mapped to Assessed Course Ability-Based Outcome

\section{Survey Question}

Ability-Based

In this course, I communicated effectively using multiple strategies

Outcome (Table 1)

I improved my ability to create a patient-centered assessment and recommend a therapeutic plan from 4,5

the pre-work assignment to Round 1 of the CPCC

Upon completion of this course, I feel confident that my performance in APPE 6 and APPE 7 will improve Clinical Pharmacy Case Conference

I improved my ability to communicate via verbal presentations throughout this course (eg, from first $1,2,4$ presentation [DI assignment] to last presentation [Clinical Pearl])

The DI activities improved my ability to retrieve, evaluate and use professional and lay information in a critical and scientific manner

Based on the activities in this course, I am more confident in my ability to communicate relevant pharmacotherapy information succinctly

In this course, I learned from my classmates

$1,2,3,4,5$

4,5

3,4

$1,2,3,4,5$

4

Abbreviations: $\mathrm{CPCC}=$ clinical pharmacy case conference, $\mathrm{APPE}=$ advanced pharmacy practice experience, $\mathrm{DI}=\mathrm{drug}$ information

each of the seven post-course survey questions were positive (Table 4 ), with $>80 \%$ of students and $>85 \%$ of faculty agreeing or strongly agreeing with all statements. Faculty responses were consistently higher than student responses for each of the statements evaluated. Correlational analyses assessed the relationship between student responses to the survey questions that evaluated course activities and the two statements related to confidence.

Table 4. Level 2 Data (Learning): Student and Faculty Response to Assessed Course Ability-Based Outcome Statements



\begin{tabular}{|c|c|c|c|c|c|c|}
\hline & \multicolumn{6}{|c|}{$\mathbf{N}(\%)$} \\
\hline & Unable to Comment ${ }^{*}$ & Strongly Disagree & Disagree & Agree & Strongly Agree & $p$ value \\
\hline \multicolumn{7}{|c|}{ In this course, I (students) communicated effectively using multiple strategies } \\
\hline Student Response & N/A & $0(0.0)$ & $6(4.3)$ & $89(63.6)$ & $45(32.1)$ & \multirow{2}{*}{.071} \\
\hline Faculty Response & 5 & $0(0.0)$ & $1(5.0)$ & $8(40.0)$ & $11(55.0)$ & \\
\hline \multicolumn{7}{|c|}{$\begin{array}{l}\text { I (students) improved my (their) ability to create a patient-centered assessment and recommend a therapeutic plan from the } \\
\text { pre-work assignment to Round } 1 \text { of the Clinical Pharmacy Case Conference }\end{array}$} \\
\hline Student Response & $\mathrm{N} / \mathrm{A}$ & $2(1.4)$ & $16(11.4)$ & $90(64.3)$ & $32(22.9)$ & \multirow[t]{2}{*}{.009} \\
\hline Faculty Response & 12 & $0(0.0)$ & $1(7.7)$ & $4(30.8)$ & $8(61.5)$ & \\
\hline \multicolumn{7}{|c|}{ Upon completion of this course, I feel confident that my (students') performance in APPE 6 and APPE 7 will improve } \\
\hline Student Response & N/A & $1(0.7)$ & $24(17.1)$ & $94(67.1)$ & $21(15.0)$ & \multirow[t]{2}{*}{.001} \\
\hline Faculty Response & 7 & $0(0.0)$ & $0(0.0)$ & $10(55.6)$ & $8(44.4)$ & \\
\hline \multicolumn{7}{|c|}{$\begin{array}{l}\text { I (students) improved my (their) ability to communicate via verbal presentations throughout this course (eg, from first presentation } \\
\text { [Drug Information assignment] to last presentation [Clinical Pearl]) }\end{array}$} \\
\hline Student Response & $\mathrm{N} / \mathrm{A}$ & $1(0.7)$ & $27(19.3)$ & $82(58.6)$ & $30(21.4)$ & \multirow[t]{2}{*}{.001} \\
\hline Faculty Response & 15 & $0(0.0)$ & $0(0.0)$ & $3(30.0)$ & $7(70.0)$ & \\
\hline \multicolumn{7}{|c|}{$\begin{array}{l}\text { The Drug Information activities improved my (the students') ability to retrieve, evaluate and use professional and lay information } \\
\text { in a critical and scientific manner }\end{array}$} \\
\hline Student Response & $\mathrm{N} / \mathrm{A}$ & $1(0.7)$ & $22(15.7)$ & $87(62.1)$ & $30(21.4)$ & \multirow[t]{2}{*}{.036} \\
\hline Faculty Response & 14 & $0(0.0)$ & $0(0.0)$ & $6(54.5)$ & $5(45.5)$ & \\
\hline \multicolumn{7}{|c|}{$\begin{array}{l}\text { Based on the activities in this course, I am more confident in my (the students') ability to communicate relevant pharmacotherapy } \\
\text { information succinctly }\end{array}$} \\
\hline Student Response & N/A & $0(0.0)$ & 25 (17.9) & $87(62.1)$ & $28(20.0)$ & \multirow[t]{2}{*}{.027} \\
\hline Faculty Response & 5 & $0(0.0)$ & $3(15.0)$ & $7(35.0)$ & $10(50.0)$ & \\
\hline \multicolumn{7}{|c|}{ In this course, I (students) learned from my (their) classmates } \\
\hline Student Response & N/A & $0(0.0)$ & $2(1.4)$ & $90(64.3)$ & $48(34.3)$ & \multirow[t]{2}{*}{.008} \\
\hline Faculty Response & 1 & $0(0.0)$ & $0(0.0)$ & $9(37.5)$ & $15(62.5)$ & \\
\hline
\end{tabular}

Abbreviations: $\mathrm{SD}=$ standard deviation, $\mathrm{CI}=$ confidence interval, $\mathrm{APPE}=$ advanced pharmacy practice experience

*Unable to comment responses are not included in the calculation and were treated as missing data

Scale: $4=$ strongly agree, $3=$ agree, $2=$ disagree, $1=$ strongly disagree, $0=$ unable to comment 


\section{American Journal of Pharmaceutical Education 2018; 82 (10) Article 6460.}

(Table 5). Positive correlations between both confidence statements and course activities were demonstrated.

\section{Level 3 Data: Behavior}

Changes in select parameters of student performance were used to evaluate behavior for Level 3 analysis. Specifically, the influence of faculty feedback on student performance was measured. Communication competency was assessed by determining the change in communication scores from the beginning to the end of the course.

Student performance in the CPCC and DI components increased after faculty feedback was provided. For the CPCC component, the pre-work assignment mean score was $84.2 \%$ (SD 12.2), and increased to $89.6 \%$ (SD $13.8)$ for the in-class components $(p<.001)$. For the DI assignment, the mean pre-work score increased from $84.9 \%$ (SD 13.7) to a mean of $90.5 \%$ (SD 15) for the inclass activity $(p=.001)$.

Two course ABOs (professionalism and communication) are consistently evaluated throughout all course components and assignment, using standardized assignment rubrics for these two components. Average scores for professionalism were $>97 \%$ for all students.
Similarly, student performance related to communication was high for each course component, as evidenced by mean scores: CPCC, 94\% (SD 11.9); DI assignment, 85\% (SD 18.4); and Clinical Pearl, 91.3\% (SD 11.7). Communication was significantly higher in the second and third presentation compared with the first in-class presentation (Table 6). Additional analyses indicated an association between students with improved communication performance and self-perception of improvement.

\section{Level 4 Data: Results}

The impact of this course on the curriculum was considered when the renewed curriculum was developed. Analysis of student performance within the Intersession course is considered by the SSPPS' Assessment Committee and Curriculum Committee as an ongoing effort to improve the renewed curriculum. Three items from the annual course evaluation survey were used to assess the course's impact on the curriculum from the student perspective. Student responses using a 1 (never) to 5 (always) point Likert scale, indicate that the course complemented what was learned in other courses (mean 4.3; SD .77), the course was designed in a manner to meet course outcomes

Table 5. Correlation Between Course Activities and Student Confidence

Correlation (r-value)

n this course, I communicated effectively using multiple strategies

I improved my ability to create a patientcentered assessment and recommend a therapeutic plan from the pre-work assignment to Round 1 of the Clinical Pharmacy Case Conference

I improved my ability to communicate via verbal presentations throughout this course (eg, from first presentation to last presentation)

The Drug Information activities improved my ability to retrieve, evaluate and use professional and lay information in a critical and scientific manner
Course Activity Survey Statement

Upon completion of this course, I feel confident that my performance in APPE 6 and APPE 7 will improve

In this course, I learned from my classmates

Abbreviations: APPE $=$ advanced pharmacy practice experience All correlations significant; $\mathrm{p}<0.0001$ (2-tailed)

0.47
Based on the activities in this course, I am more confident in my ability to communicate relevant pharmacotherapy information succinctly

$0.60 \quad 0.66$ 


\section{American Journal of Pharmaceutical Education 2018; 82 (10) Article 6460.}

Table 6. Communication Comparative Data_-Paired Samples Test

\begin{tabular}{lccc}
\hline & $\begin{array}{c}\text { Mean } \\
\text { Difference } \\
(\mathbf{\%})\end{array}$ & $\begin{array}{c}\text { 95\% Confidence } \\
\text { Interval of } \\
\text { Difference }\end{array}$ & $\begin{array}{c}\boldsymbol{p} \\
\text { value }\end{array}$ \\
\hline $\begin{array}{c}\text { Drug Information } \\
\text { to Clinical }\end{array}$ & 8.0 & $4.7-11.2$ & $<.001$ \\
$\begin{array}{l}\text { Pharmacy Case } \\
\text { Conference }\end{array}$ & & & \\
$\begin{array}{c}\text { Drug Information } \\
\text { to Clinical Pearl }\end{array}$ & 5.4 & $1.9-8.9$ & .003 \\
\hline
\end{tabular}

Abbreviations: $\mathrm{SD}=$ standard deviation, $\mathrm{CI}=$ confidence interval

(mean 4.3; SD .59), and APPE experiences helped meet course outcomes (mean 4.3; SD .68).

\section{DISCUSSION}

This Intersession course is a culminating experience for systematic evaluation of individual P4 students' competence of five curricular ABOs. A novel aspect of this course is that this standardized assessment is provided by faculty and is at a near-terminal level. The workability of assessing students is dependent upon, and facilitated by real-world patient experiences encountered during APPEs. A comprehensive assessment using Kirkpatrick's four level model demonstrated success of this course with the inaugural offering in 2016. The Intersession course is an ongoing required component of the SSPPS curriculum.

As supported by the AACP 2012-2013 Academic Affairs Standing Committee, a fundamental concept of the CAPE Educational Outcomes is that pharmacy programs should include a comprehensive assessment plan to ensure achievement of the outcomes by the end of the professional program. ${ }^{6}$ This was accomplished by placing the Intersession course strategically near the end of the APPE year. The multipronged course approach holds students accountable for prior learning and real-world experiences from the practice environment. The reassessment of students' abilities to meet key ABOs within the APPE year and a course structure with faculty assessment is novel. Many pharmacy schools complete assessments of student outcomes by the end of the professional programs within individual APPE rotations. The benefit of this faculty-led Intersession course model is that expectations can be more uniform and consistent. Moreover, each student fully engages in self-assessment and the opportunity to learn from peers using real-world examples within the on-campus live portion of this course.

Early didactic courses within the curriculum focus on developing students' abilities to provide accurate, succinct, and critical assessments and plans of patient cases.
Similar to other programs, the curriculum at SSPPS includes a capstone course that assesses student performance in many clinical areas. ${ }^{7}$ However, students' skills and abilities are assessed prior to the start of the P4 year in the capstone course. Therefore, it is not a terminal assessment of competence because students further develop and refine skills during the APPE program. One study suggested that the APPE learning environment may not provide students with adequate opportunities to develop certain competencies related to creating assessments and plans. ${ }^{8}$ This Intersession course mitigates this limitation by re-enforcing that learning opportunities from the didactic curriculum and APPEs are capitalized upon by requiring a formal case presentation and other required assignments. Electronic portfolios have been suggested as beneficial in developing clinical skills in the APPE setting, based on student opinions. ${ }^{9}$ However, the innovative approach within the Intersession course provides consistency through direct observation and feedback of student performance.

Drug information skills are an important foundational component of pharmacy curriculum. ${ }^{10}$ Although covered in the didactic curriculum at many pharmacy schools, not all programs offer APPE rotations focused in DI. ${ }^{11}$ Other authors have published innovative approaches to teaching DI, including a jigsaw approach where students work in a group setting and student-peer mentoring. ${ }^{12,13}$ However, this Intersession course allows for a formal and systematic faculty assessment of DI skills during the APPE year. This approach is novel through incorporation of faculty assessment and feedback applied from pre-work to in-class work, application and sharing of DI skills from real-life APPE scenarios, exchanging DI questions with peers with feedback from peer-to-peer discussion and instruction, and a timed in-class activity (4 hours) that more closely mimics pharmacy practice. Requiring students to discuss DI questions and answers in a small group setting also provides the opportunity for students to learn valuable clinical information stemming from a variety of practice sites.

Didactic content focusing on clinical pearls within an elective pharmacy course has been described in the literature. ${ }^{14}$ Clinical pearl information is typically anecdotal, but can also contain evidence for use from small trials and/or data extrapolated from larger, related trials. The benefit of a clinical pearl is that it concisely communicates practical practice points. Like other schools, the SSPPS curriculum prepares students with the skills to investigate and present information related to these clinical pearls, typically within the DI coursework. However, this Intersession course includes clinical pearls within the APPE year. Beyond a formal assessment by faculty, this 


\section{American Journal of Pharmaceutical Education 2018; 82 (10) Article 6460.}

also exposes students to a variety of medication updates and stresses the importance of lifelong learning. Students universally reported value in this assignment, noting surprise at how much there is to learn and how quickly things change in pharmacy practice.

Reflection is a tool to engage in critical self-assessment, which is required prior to engaging in deliberate selfimprovement. Reflection also increases self-awareness of an individual's beliefs, biases, and decision-making skills, which are essential to developing professional identity as a clinical practitioner. ${ }^{15}$ Students need both self-awareness and self-assessment skills to develop the skills of lifelong learning and continuous professional development required in post-graduate careers. The reflection component of this course is an opportunity for students to reflect on near-terminal abilities, share past experiences with underclassmen in a professional manner, and recognize the importance of lifelong learning.

The design of the Intersession course enables collective assessments of all students' performance that, in part, reflects prior learning. Therefore, the pedagogy of this course affords the opportunity to use the course as a programmatic assessment tool. This approach allows for identification of global strengths and weaknesses of preceding courses within the curriculum that target the same ABOs. Based on this information, quality improvement of the curriculum at SSPPS can occur. For example, identification of curricular threads such as DI can be made more consistent between courses allowing for a clear progression of skills from $\mathrm{P} 1$ to $\mathrm{P} 4$ year.

The SSPPS ABO, "maintain professional competency and professional stewardship," has been challenging to assess. This outcome includes the ability to identify and analyze emerging issues and the ability to self-assess learning needs and design, implement, and evaluate strategies to promote intellectual growth and continued professional competence. Moreover, Domain 4 of the CAPE Educational Outcomes includes personal and professional development and focuses on self-awareness. ${ }^{3}$ The concepts of lifelong learning are embedded within all Intersession course components and activities. However, students deliberately expressed an appreciation that the course components broadened knowledge bases, enhanced learning, and purposefully emphasized lifelong learning. Student survey data and professional reflection letters anecdotally indicated a realization that keeping up with the significant advances in pharmacotherapy and clinical practice is challenging. Students clearly demonstrated increased awareness of the importance of lifelong learning within this course.

This Intersession course achieved success during the inaugural year and remains a required course within the
SSPPS curriculum. Revisions were made for the second year, but the main framework and philosophy remain. Communication of course goals and objectives to students now focuses more clearly on the expectations and purpose of this course. Some students were under the wrong impression that the primary purpose of this Intersession course was preparation for board examinations. Greater emphasis is now placed on purposefully communicating that this course is a near-terminal assessment of student competency related to specific ABOs. Improvements and refinements to the grading rubrics were made to provide additional clarity and balance, as well as to improve efficiency associated with providing feedback and completing assessments. Importantly, the remediation and reassessment structure was revised. For the first year, the need for remediation was based on overall course performance. However, in this model it was possible for students to perform well in the course at large while failing to demonstrate satisfactory competency on the individual components. To better assess each individual assignment and ABOs, the remediation and reassessment model now requires a passing grade on each of the four individual course component regardless of final course grade. Individual remediation plans are made for each student failing to meet expectations on any of the four individual components.

This course is generalizable and can be implemented in other pharmacy programs using this experience as a model. Programs implementing a new or renewed curriculum can plan for the implementation of an intersession course. A major consideration is the projected impact on APPE sites. This Intersession course required that no students were scheduled for an APPE during one APPE slot. At SSPPS, the solution was to incorporate an advanced Introductory Professional Practice Experience (aIPPE) for P3 students, a full-time 6-week clinical rotation that occurs in the beginning of the spring semester, into this time slot. It is prior to the final P3 didactic courses in that semester, which includes a clinical capstone course. The SSPPS has had success with clinical capstone courses in the previous curriculum, and is included in the renewed curriculum. ${ }^{16}$ However, the aIPPE provides students with additional clinical experiences to make the capstone experience more successful. This would not have been possible if the Intersession course had not freed up these clinical rotation spots.

Implementation of similar intersession courses can occur for pharmacy schools that are not undergoing curriculum renewal. This may require an adapted model that may not include an aIPPE for P3 students, or may use a staggered model with P4 students scheduled for different blocks of time to ensure that a cohort of students are 


\section{American Journal of Pharmaceutical Education 2018; 82 (10) Article 6460.}

scheduled during open APPE rotations. An additional consideration is the need for APPE students to travel back to campus. This may be a challenge for those students completing APPEs at a distance from campus. Of note, immediately after completion of the Intersession course, APPE students have four weeks until the start of the next APPE. During this time, those who are pursuing residency training can schedule interviews with little to no conflict with scheduled educational commitments. Students and faculty viewed this aspect as a significant advantage within the curricular model, as residency interviews often interrupted APPE rotations in the previous curriculum.

\section{CONCLUSION}

This Intersession course achieved overall success in its inaugural year. The course had several innovative components. The overall structure provided a unique opportunity for faculty to assess student achievement of curricular ability-based outcomes at a near-terminal level, after completion of five of seven APPEs. All students received extensive faculty feedback. Students who did not demonstrate competence received clear direction in the form of feedback allowing the opportunity to improve and demonstrate competence after completion of the final two APPEs. The rigorous and systematic assessment of competence among all students in the final year of training provided insight into the success of the University of Colorado's curriculum. The promotion of student awareness of lifelong learning through use of clinical assessments, reflection and Value Added Sessions was an unexpected but an important discovery. Intersession courses during the P4 experiential year can be implemented at other pharmacy schools and colleges using the framework implemented at the University of Colorado as a model.

\section{ACKNOWLEDGMENTS}

The authors would like to thank the University of Colorado Skaggs School of Pharmacy and Pharmaceutical Sciences faculty who participated in this course and Ms. Agnes Anderson who provided administrative support. This innovation was presented at the 2016 AACP Annual Meeting in Anaheim, CA as the 2016 AACP Innovations in Teaching Competition winner, and the authors express gratitude for this prestigious recognition.

\section{REFERENCES}

1. Cudnik ML, Gallegos PJ, Costa AJ. InterSession course: interdisciplinary education by pharmacy and medical school faculty. 108TH Annual Meeting of the American Association of Colleges of Pharmacy, Orlando, Florida, July 14-17, 2007. Am J Pharm Educ. 2007;71(3):Article 60.

2. Fenton $\mathrm{C}$, Loeser $\mathrm{H}$, Cooke M. Intersessions: covering the bases in the clinical year. Acad Med. 2002;77(11):1159.

3. Medina MS, Plaza CM, Stowe CD, et al. Center for the Advancement of Pharmacy Education 2013 educational outcomes. Am J Pharm Educ. 2013;77(8):Article 162.

4. Kirkpatrick DL. Techniques for evaluating training programs. J Am Soc Training Directors. 1959;13:3-9.

5. Praslova L. Adaptation of Kirkpatrick's four level model of training criteria to assessment of learning outcomes and program evaluation in higher education. Educ Asse Eval Acc. 2010;22(3): 215-225.

6. Medina MS, Plaza CM, Stowe CD, et al. Report of the 2012-2013 Academic Affairs Standing Committee: revising the Center for the Advancement of Pharmacy Education (CAPE) Educational Outcomes 2013. Am J Pharm Educ. 2013;77(8):Article S8.

7. Hirsch AC, Parihar HS. A capstone course with a comprehensive and integrated review of the pharmacy curriculum and student assessment as a preparation for advanced pharmacy practice experiences. Am J Pharm Educ. 2014;78(10):Article 192.

8. Kassam R. Evaluation of pharmaceutical care opportunities within an advanced pharmacy practice experience. Am J Pharm Educ. 2006;70(3): Article 49.

9. McDuffie CH, Sheffield MC, Miller MS, Duke LJ, Rogers SP. Web-based portfolios for pharmaceutical care plans during advanced pharmacy practice experiences. Am J Pharm Educ. 2010;74(4): Article 59.

10. Cole SW, Berensen NM. Comparison of drug information practice curriculum components in US colleges of pharmacy. Am J Pharm Educ. 2005;69(2):Article 34.

11. Wang F, Troutman WG, Seo T, Peak A, Rosenberg JM. Drug information education in doctor of pharmacy programs. Am J Pharm Educ. 2006;70(3):Article 51.

12. Earl GL. Using cooperative learning for a drug information assignment. Am J Pharm Educ. 2009;73(7):Article 132.

13. Rodis JL, Backo J, Schmidt BM, Pruchnicki MC. Student-peer mentoring on a drug information response. Am J Pharm Educ. 2014;78(2):Article 38.

14. Romanelli F. An elective course to introduce clinical pearls related to commonly prescribed medications. Am J Pharm Educ. 2009;73(7):Article 117.

15. Wald HS, Reis SP. Beyond the margins: reflective writing and development of reflective capacity in medical education. J Gen Intern Med. 2010;25(7):746-749.

16. Saseen JJ, Linnebur SA, Borgelt LM, Trujillo J, Fish DN, Mueller S. A pharmacotherapy capstone course to target student learning and programmatic curricular assessment. Am J Pharm Educ. 2017;81(3):Article 45. 